DOI: https://doi.org/10.47405/mjssh.v5i10.511

\begin{tabular}{|c|c|}
\hline 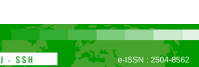 & Malaysian Journal of Social Sciences and Humanities (MJSSH) \\
\hline $\begin{array}{l}\text { Malaysian Journal of } \\
\text { Solaci sciences and } \\
\text { and }\end{array}$ & Volume 5, Issue 10, October 2020 \\
\hline (MJ-sSH) & e-ISSN : 2504-8562 \\
\hline & $\begin{array}{l}\text { Journal home page: } \\
\text { www.msocialsciences.com }\end{array}$ \\
\hline
\end{tabular}

\title{
Budaya Sekolah: Hubungannya dengan Komitmen Guru
}

\author{
Lily James Billy', Muhamad Suhaimi Taat ${ }^{1}$ \\ 1Fakulti Psikologi dan Pendidikan, Universiti Malaysia Sabah (UMS) \\ Correspondence: Lily James Billy (lilybilly74@yahoo.com)
}

\begin{abstract}
Abstrak
Komitmen guru amat penting bagi memastikan kemenjadian murid seperti mana dalam PPPM 20132025. Kajian ini adalah untuk mengenal pasti hubungan budaya sekolah terhadap komitmen guru sekolah rendah di bahagian pedalaman atas negeri Sabah, Malaysia. Kajian berbentuk bukan jenis eksperimental ini menggunakan kaedah tinjauan dan menggabungkan tiga teknik pensampelan kebarangkalian untuk mendapatkan sampel. Dua set soal selidik iaitu TCM Employee Commitment Survey (Meyer \& Allen, 2004) dan Soal Selidik Budaya Organisasi (Ipek, 1999) digunakan untuk mendapatkan data daripada 458 responden guru. Data dianalisis menggunakan perisian IBM SPSS Statistics 25.0. Berpandukan analisis deskriptif, didapati budaya sekolah berada pada tahap tinggi. Manakala komitmen guru berada pada tahap sederhana. Berdasarkan analisis statistik inferensi, ujian-t bagi budaya sekolah berdasarkan jantina adalah tidak signifikan $(t=1.434, \mathrm{df}=456, \mathrm{p}>0.05)$ yang menunjukkan tidak terdapat perbezaan yang signifikan budaya sekolah berdasarkan jantina. Manakala hasil ujian-t bagi komitmen guru berdasarkan jantina menunjukkan hasil yang signifikan $(\mathrm{t}=2.018$, df $=456, \mathrm{p}<0.05)$ yang menunjukkan terdapat perbezaan yang signifikan komitmen guru berdasarkan jantina. Melalui ujian Korelasi Pearson didapati terdapat hubungan signifikan yang positif dengan kekuatan yang sederhana $(\mathrm{r}=0.427, \mathrm{p}<0.01)$ budaya sekolah dengan komitmen guru. Kajian mencadangkan agar budaya sekolah diamalkan pada tahap tinggi memandangkan terdapat hubungan signifikan yang positif antara budaya sekolah dengan komitmen guru.
\end{abstract}

Kata kunci: komitmen guru, budaya sekolah, kemenjadian murid

\section{School Culture: Its Relationship with Teachers' Commitment}

\begin{abstract}
Teachers' commitment is very important to ensure the student excel as stated in Malaysian Education Blueprint 2013-2025. This research was to identify the relationship between school culture and teachers' commitment in upper interior division of Sabah. This non-experimental study used a survey method and combined three probability sampling techniques in obtaining samples. Data were collected using two sets of adapted questionnaires from the TCM Employee Commitment Survey (Meyer \& Allen , 2004) and organizational culture questionnaire (Ipek, 1999) and administered to 458 teachers. The data were analysed using the IBM SPSS Statistical 25.0 software. Based on descriptive analysis, school culture was at high level while teachers' commitment was at moderate level. Based on the inferential analysis, $t$ - test based on school culture showed insignificant finding $(t=1.434, \mathrm{df}=456$, $\mathrm{p}>0.05)$, which indicated there was no difference school culture based on gender. While t- test based on teachers' commitment showed significant finding $(\mathrm{t}=2.018, \mathrm{df}=456, \mathrm{p}<0.05)$, which showed there was a difference teachers' commitment based on gender. Through a Pearson Correlation test, there was a
\end{abstract}


significant positive relationship between school culture and teachers' commitment with average strength $(\mathrm{r}=0.427, \mathrm{p}<0.01)$. This study suggests teachers to have high level of school culture as it will increase the teachers' commitment.

Keywords: teachers' commitment, school culture, student excel

\section{Pengenalan}

Komitmen guru amat penting terhadap kualiti pendidikan (Nordin, Darmawan \& Keeves, 2010). Hal ini kerana guru yang mempunyai tahap komitmen di sekolah yang tinggi merupakan guru yang bertanggungjawab (Relly, 2015; Shafiq \& Rana, 2016). Justeru komitmen guru perlu diberi perhatian serius memandangkan ia berupaya meningkatkan pencapaian akademik pelajar dan prestasi sekolah (Mohamad, Zakaria \& Nasir, 2017; Stan, 2013; Siti Fairuz, Norshidah, Afni \& Norsiah, 2013; Hanaysha, 2016; Karim \& Rehman, 2012; Cheasakul \& Varma, 2016; Hayden, 2011; Ambotang \& Bayong, 2018).

Budaya sekolah berupaya meningkatkan komitmen guru di sekolah (Manetje \& Martins, 2009; Meyer \& Allen, 1991; Rahayu, 2012; Sabir, Razzaq \& Yameen, 2010). Hal ini disebabkan budaya sekolah yang sebati dengan diri akan memudahkan guru- guru bekerjasama antara satu dengan lain dan menggelakkan konflik (Baharom, 2012; Daud, 2007; Shaqholi, Zabihi, Atefi \& Moayedi, 2011). Selain itu budaya sekolah dan komitmen guru yang baik juga akan memberi kesan kepada sikap akademik pelajar (Muhamad Suhaimi \& Gladys, 2014).

Isu yang timbul berkaitan komitmen guru ialah pencapaian murid yang kurang memberansangkan, ponteng kerja dan lewat hadir bertugas, menyalahgunakan surat kebenaran cuti dan cenderung mempunyai tingkah laku kerja yang negatif (Hayden, 2011; Shafiq \& Rana, 2016; Nurharani \& Norshidah, 2012; Shapira-Lishchinsky \& Rosenblatt, 2010; Nordin, 2012).

Literatur menunjukkan masih kurang penyelidikan dijalankan berkaitan variabel budaya sekolah dan komitmen guru dalam bidang pendidikan (Selden, 2014) khususnya di pedalaman atas negeri Sabah (Hanaysha, 2016). Sehingga kini terdapat kekurangan dalam kajian berkaitan tajuk komitmen sama ada di Barat, di Malaysia mahupun di Indonesia (Iskandar Rohaty Mohd. Majzub \& Zuria Mahmud, 2009). Justeru kajian ini dilakukan untuk memenuhi kelompangan tersebut.

\section{Objektif Kajian}

i Mengenal pasti perbezaan skor min budaya sekolah dan komitmen guru berdasarkan jantina.

ii Mengenal pasti hubungan budaya sekolah dengan komitmen guru.

\section{Hipotesis Kajian}

Ho1: Tidak terdapat perbezaan skor min yang signifikan budaya sekolah berdasarkan jantina.

Ho2: Tidak terdapat perbezaan skor min yang signifikan komitmen guru berdasarkan jantina.

Ho3: Tidak terdapat hubungan yang signifikan budaya sekolah dengan komitmen guru.

\section{Sorotan Literatur}

Literatur menunjukkan pelbagai definisi komitmen organisasi antaranya kekuatan relatif terhadap pengecaman dan penglibatan ahli terhadap organisasi tertentu (Mowday, Steers \& Porter, 1979); keterikatan psikologi yang dirasakan oleh ahli terhadap organisasi (O'Reilly \& Chatman, 1986); keadaan psikologi yang mengikat ahli kepada organisasi (Allen \& Meyer, 1990); menyifatkan 
hubungan ahli dengan organisasi (Ipek, 2010); penglibatan ahli dalam organisasi (Helvaci \& Kiliçoglu, 2018); tahap integrasi dan pengecaman yang dirasakan oleh ahli terhadap organisasi (Palta, 2019).

Konsep komitmen organisasi berpunca daripada keinginan individu untuk menjadi ahli, keupayaan untuk mempercayai dan menerima nilai dan objektif dan keupayaan untuk memberikan yang terbaik kepada organisasi (Enginyurt, Cankaya, Aksay, Tunc, Koc, Bas \& Ozer, 2016).

Teori taruhan sampingan Becker (1960) menjelaskan komitmen organisasi akan semakin meningkat atau bertambah sekiranya terdapat pelaburan berupa masa, tenaga dan wang dan taruhan berupa pencen, ganjaran, status dan kekananan jawatan. Semakin besar pelaburan yang diberikan dan taruhan yang diterima maka semakin payah untuk meninggalkan sesebuah organisasi.

Kajian ini menggunakan model tiga komponen komitmen organisasi yang dibangunkan oleh Meyer dan Allen (1997). Berpandukan pada model tersebut terdapat tiga komponen komitmen organisasi. Pertama adalah komitmen afektif iaitu keterikatan emosi terhadap organisasi. Kedua merupakan komitmen berterusan iaitu kebimbangan terhadap kos yang bakal ditanggung ahli sekiranya meninggalkan organisasi dan tiada usaha melakukan pekerjaan lain. Ketiga merupakan komitmen normatif iaitu keterikatan berpunca daripada perasaan terhutang budi terhadap organisasi dan berasa wajib terus bekerja disebabkan berhadapan dengan tekanan daripada orang lain.

Model budaya organisasi Harrison (1993) yang terdiri daripada konstruk budaya kuasa, budaya peranan, budaya pencapaian dan budaya sokongan digunakan untuk menjelaskan budaya sekolah. Budaya kuasa merujuk kepada guru besar yang bertanggungjawab untuk mengurus sekolah dan guruguru. Budaya peranan merujuk kepada peraturan, polisi, prosedur dan deskripsi tugas yang menjadi panduan kepada guru dan sekolah. Budaya pencapaian merujuk kepada guru dan sekolah yang mempunyai visi dan misi yang sama. Manakala budaya menyokong merupakan karakteristik utama dalam perkongsian kepercayaan antara guru dengan sekolah.

\section{Metod Kajian}

Kajian ini berbentuk jenis bukan eksperimental yang menggunakan kaedah tinjauan sampel. Pendekatan kuantitatif digunakan bagi memperolehi data dengan menitik beratkan kebolehpercayaan serta kesahannya. Populasi kajian adalah guru sekolah rendah harian biasa kerajaan seramai 2686 orang. Berlandaskan jadual Krejcie dan Morgan (1970) sebanyak 458 set borang soal selidik telah diedar kemudian diproses. Sampel diperolehi dengan menggabungkan beberapa pensampelan kebarangkalian meliputi kaedah berstrata, kluster dan rawak mudah.

Komitmen guru diukur menggunakan TCM Employee Commitment Survey (Meyer \& Allen, 2004) manakala budaya sekolah diukur menggunakan Soal Selidik Budaya Organisasi oleh Ipek (1999). Kedua-dua instrumen berkenaan telah diberi kebenaran untuk diguna dan diadaptasi oleh pemilik asal. Kedua- dua instrumen berkenaan juga telah menjalani back to back translation.

Kajian rintis telah dijalankan untuk menguji kesahan konstruk (analisis faktor penerokaan) dan kebolehpercayaan (Alpha Cronbach) alat ukur kajian. Kesempurnaan atau kecukupan item telah ditentukan terlebih dahulu sebelum melakukan faktor analisis. Pallant (2013) berpendapat terdapat dua pengukuran statistik yang berupaya menentukan jika data berkenaan sesuai atau tidak menjalankan faktor analisis iaitu sukatan kecukupan pensampelan Kaiser-Meyer-Olkin (Kaiser-Meyer-Olkin measure of sampling adequacy) dan ujian kesferaan Bartlett (Bartlett's test of sphericity). Ujian Kaiser-Meyer-Olkin (KMO) bertujuan menentukan kesempurnaan atau kecukupan item atau sampel soalan bagi menentukan sama ada data berkenaan sesuai dijalankan analisis faktor atau tidak. Ghazali et al. (2016) menegaskan penentuan aras diterima ialah nilai $>.600, \mathrm{sig}=\mathrm{p}<.000$.

Kajian ini akan menerima nilai KMO yang lebih besar daripada 0.50 kerana beberapa sarjana menyatakan nilai tersebut adalah sesuai dan boleh diterima (Hair, Black, Babin, Anderson \& Tatham, 1998; Chua, 2009). Menurut Lay, Khoo dan Ley (2016) nilai ujian kesferaan Bartlett yang besar serta 
signifikan penting bagi membolehkan analisis faktor dilaksanakan. Pallant (2007) berpendapat Ujian Bartlett's Test of Sphericity berupaya mengenal pasti sama ada korelasi item memadai bagi melakukan analisis faktor dengan nilai kesignifikan $\mathrm{p}<.05$.

Bagi tujuan kesahan, sebanyak 18 item variabel komitmen guru meliputi tiga konstruks iaitu komitmen afektif, berterusan dan normatif dimuatkan untuk dianalisis. Keputusan ujian kesferaan Bartlett didapati besar dan signifikan $\left(x^{2}=969.874, d f=153, p<0.05\right)$, manakala, nilai ujian sukatan kecukupan pensampelan Kaiser-Meyer-Olkin adalah 0.81, jauh lebih tinggi daripada nilai 0.60 yang disarankan. Manakala sebanyak 36 item variabel budaya sekolah (budaya kuasa, peranan, pencapaian dan sokongan) dimuatkan untuk dianalisis. Keputusan ujian kesferaan Bartlett adalah besar dan signifikan $\left(\mathrm{x}^{2}=2483.075, \mathrm{df}=630, \mathrm{p}<0.05\right)$. Nilai ujian Kaiser-Meyer-Olkin adalah 0.84. Oleh itu, sifat kebolehfaktoran dapat diandaikan dan ujian kebolehpercayaan boleh dijalankan. Berdasarkan kepada dapatan analisis faktor terdapat empat item yang mempunyai cross loading manakala dua item mempunyai nilai faktor muatan dibawah 0.4. Ini menjadikan jumlah item bermasalah yang perlu digugurkan daripada instrumen soal selidik budaya organisasi adalah sebanyak enam item.

Keputusan ujian kebolehpercayaan menunjukkan nilai pekali Alpha Cronbach variabel komitmen guru ialah 0.88 manakala budaya sekolah adalah 0.93. Hal ini memberikan petanda bahawa kebolehpercayaan item konstruk kajian adalah tinggi dan sesuai berpandukan saranan Fraenkel dan Wallen (1996) dan Mohd. Majid konting (2000).

\section{Hasil Kajian}

\section{Perbezaan Skor Min Budaya Organisasi Berdasarkan Jantina}

\section{Hipotesis Nul 1 (Ho1) : Tidak terdapat perbezaan skor min yang signifikan budaya sekolah berdasarkan jantina.}

Hipotesis kajian ini (Ho1) diuji menggunakan teknik perbandingan group statistics bertujuan membandingkan skor min kumpulan melalui Ujian-t (Independent Samples Test). Aras signifikan yang ditetapkan adalah $\mathrm{p}<0.05$. Manakala ujian persamaan varian Levene digunakan bertujuan memastikan ketepatan data yang didapati. Jadual 1 menunjukkan dapatan ujian yang memaparkan hasil analisis perbandingan skor min guru lelaki dan perempuan. Analisis sampel kajian ini $(\mathrm{N}=458)$ menunjukkan terdapat perbezaan skor min sebanyak 0.053 di antara kedua-dua kumpulan responden berkaitan budaya sekolah. Skor min lelaki $(\mathrm{M}=3.991, \mathrm{SP}=0.381, \mathrm{~N}=170)$ adalah lebih tinggi berbanding skor min perempuan $(\mathrm{M}=3.938, \mathrm{SP}=0.389, \mathrm{~N}=288)$. Nilai min yang lebih tinggi bagi kumpulan responden lelaki menunjukkan mereka mempunyai persepsi terhadap budaya sekolah yang lebih tinggi berbanding perempuan. Berdasarkan dapatan ujian-t, hasil yang diperolehi adalah tidak signifikan $(\mathrm{t}=$ 1.434, df $=456, \mathrm{p}>0.05$ ). Hal ini bermaksud, Hipotesis Nul 1 (Ho1) adalah gagal ditolak. Justeru, dapatan ini menunjukkan bahawa tidak terdapat perbezaan budaya sekolah antara guru lelaki dan perempuan.

Jadual 1: Analisis Ujian -t Budaya Organisasi Berdasarkan Jantina

\begin{tabular}{|c|c|c|c|c|c|c|c|}
\hline & Variabel & $\mathbf{M}$ & SP & $\boldsymbol{F}$ & Nilai - $t$ & $d f$ & $\begin{array}{c}\text { Sig } \\
\text { (2-Hujung) }\end{array}$ \\
\hline BS & Lelaki & 3.991 & 0.381 & \multirow[b]{2}{*}{0.433} & \multirow[b]{2}{*}{1.434} & \multirow[b]{2}{*}{456} & \multirow[b]{2}{*}{0.152} \\
\hline & Perempuan & 3.938 & 0.389 & & & & \\
\hline \multicolumn{8}{|c|}{ *Signifikan pada tahap $\mathrm{p}<0.05$ (2-Hujung) } \\
\hline
\end{tabular}




\section{Perbezaan Skor Min Komitmen Guru Berdasarkan Jantina}

\section{Hipotesis Nul 2 (Ho2) : Tidak terdapat perbezaan skor min yang signifikan komitmen guru berdasarkan jantina.}

Hipotesis kajian ini (Ho2) juga diuji menggunakan teknik perbandingan group statistics bertujuan membandingkan skor min kumpulan melalui Ujian-t (Independent Samples Test). Penetapan aras signifikan adalah $\mathrm{p}<0.05$. Manakala ujian persamaan varian Levene digunakan bertujuan memastikan ketepatan data yang didapati. Analisis bagi sampel kajian ini $(\mathrm{N}=458)$ menunjukkan terdapat perbezaan skor min sebanyak min sebanyak 0.095 antara kedua- dua kumpulan responden berkaitan komitmen guru. Analisis menunjukkan skor min lelaki $(\mathrm{M}=3.599, \mathrm{SP}=0.488, \mathrm{~N}=170)$ lebih tinggi berbanding skor min wanita $(\mathrm{M}=3.504, \mathrm{SP}=0.487, \mathrm{~N}=288)$. Nilai min yang lebih tinggi bagi kumpulan lelaki menunjukkan pengamalan komitmen guru yang tinggi berbanding kumpulan responden perempuan. Berdasarkan hasil ujian-t, keputusan diperolehi menunjukkan hasil yang signifikan $(\mathrm{t}=2.018, \mathrm{df}=456$, $\mathrm{p}<0.05$ ) yang memberi makna bahawa Hipotesis Nul 2 (Ho2) adalah ditolak. Justeru dapatan ini menunjukkan bahawa terdapat perbezaan yang signifikan komitmen guru antara guru lelaki dan perempuan, dengan guru lelaki mencatatkan tahap pengamalan yang tinggi berbanding guru perempuan (Jadual 2).

Jadual 2: Analisis Ujian -t Komitmen Guru Berdasarkan Jantina

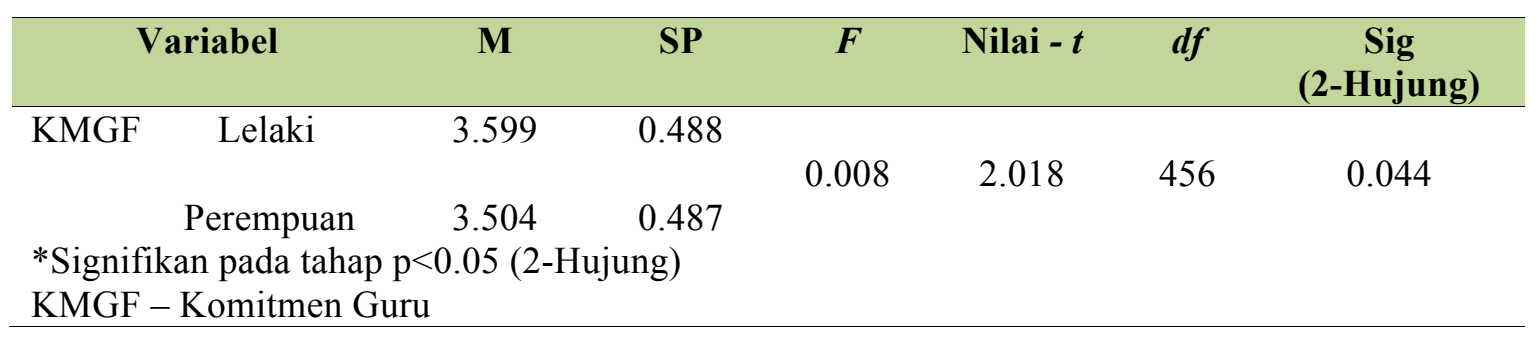

\section{Hubungan Budaya Sekolah Dengan Komitmen Guru (Objektif 2)}

\section{Hipotesis Nul 3 (Ho3) : Tidak terdapat hubungan yang signifikan variabel budaya sekolah dengan komitmen guru.}

Keputusan nilai koefisien ujian korelasi Pearson bagi jumlah sampel kajian $(\mathrm{N}=458)$ adalah ditunjukkan dalam Jadual 3. Dapatan kajian membuktikan wujudnya hubungan positif yang signifikan antara budaya sekolah $(\mathrm{r}=0.427, \mathrm{p}<0.01)$ dengan komitmen guru. Kekuatan hubungan didapati sederhana berpandukan indeks korelasi seperti dicadangkan oleh Cohen et al. (2007). Oleh kerana dapatan menunjukkan hubungan yang signifikan antara variabel kajian, maka Hipotesis Nul 3 (Ho3) ditolak. Justeru, hasil kajian menunjukkan terdapat hubungan positif yang signifikan variabel budaya sekolah dengan variabel komitmen guru.

Jadual 3: Analisis Korelasi Pearson di Antara Budaya Sekolah Dengan Komitmen Guru

\begin{tabular}{lll}
\multicolumn{1}{c}{ Variabel } & & BS \\
${$\cline { 3 - 3 }$} }$ & Korelasi Pearson & $0.427 * *$ \\
& $\mathrm{P}($ sig) & 0.000 \\
$* *$ Signifikan pada Tahap p $<0.01$ (2-Hujung) & \\
BS - Budaya Organisasi & \\
\hline
\end{tabular}




\section{Perbincangan Kajian}

Dapatan kajian menunjukkan terdapat perbezaan skor min yang kecil antara kedua-dua kumpulan responden berkaitan komitmen guru dengan responden lelaki mempunyai skor min yang lebih tinggi berbanding responden perempuan. Dapatan ini bercanggah dengan dapatan Messner (2017, Erdogan dan Cavli (2019) dan Sarwar dan Ashrafi (2014) yang mendapati responden perempuan mempunyai persepsi yang lebih tinggi terhadap komitmen berbanding responden lelaki.

Berdasarkan hasil ujian-t, keputusan diperolehi menunjukkan hasil yang signifikan yang memberi makna bahawa Hipotesis Nul 1 (Ho1) adalah ditolak. Hal ini bermakna terdapat perbezaan yang signifikan komitmen guru antara responden guru lelaki dan responden guru perempuan di pedalaman atas negeri Sabah. Justeru dapatan ini menunjukkan guru lelaki mempunyai persepsi yang lebih tinggi terhadap variabel komitmen guru berbanding responden guru perempuan. Dapatan kajian ini tidak sealiran atau bercanggah dengan dapatan kajian Naderi (2012) dan Palta (2019).

Terdapat jumlah guru perempuan yang lebih ramai berbanding guru lelaki di sekolah di pedalaman atas negeri Sabah iaitu jumlah guru perempuan seramai 1533 orang manakala guru lelaki seramai 1153 orang sahaja. Walau bagaimanapun guru lelaki menunjukkan persepsi yang lebih tinggi terhadap komitmen guru disebabkan mereka telah membuat pelaburan yang lebih daripada segi masa dan tenaga terhadap sekolah. Semakin banyak pelaburan yang diberikan kepada sekolah maka semakin tinggi komitmen yang terhasil.

Dapatan kajian menunjukkan terdapat perbezaan skor min yang kecil antara kedua-dua kumpulan responden berkaitan budaya sekolah. Kewujudan perbezaan nilai berkenaan biar pun agak kecil namun tetap memberikan petunjuk iaitu guru lelaki mempersepsikan budaya sekolah pada tahap tinggi berbanding guru perempuan.

Berdasarkan dapatan ujian-t, hasil kajian yang diperolehi berkaitan variabel budaya sekolah berdasarkan jantina adalah tidak signifikan. Hal ini bermakna tidak terdapat perbezaan budaya sekolah antara responden guru lelaki dan perempuan. Dapatan kajian ini disokong oleh Relly (2015), dan Jamal (2009) yang mendapati tidak terdapat perbezaan budaya sekolah berdasarkan jantina. Walau bagaimanapun kajian Mauno, Kinnunen dan Feldt (2012), Paul (2012) dan Windy (2019) mempunyai dapatan yang bercanggah dengan dapatan kajian ini.

Sekolah-sekolah di bahagian pedalaman atas negeri Sabah secara demografi menunjukkan bilangan guru lelaki yang kurang berbanding guru perempuan. Walau bagaimanapun golongan lelaki mendapat galakkan, sokongan serta kerjasama daripada rakan guru yang lain dan pentadbir di sekolah menyebabkan skor min budaya sekolah guru lelaki adalah lebih tinggi berbanding guru perempuan. Di samping itu, terdapat peraturan serta prosedur yang jelas daripada pihak pentadbir menyebabkan guru lelaki lebih mudah mengikut jangkaan serta kemahuan pihak pentadbir, yang meningkatkan budaya sekolah dalam kalangan mereka.

Dapatan daripada ujian korelasi Pearson membuktikan wujudnya hubungan positif yang signifikan antara budaya sekolah dengan komitmen guru. Berdasarkan dapatan kajian didapati kekuatan yang sederhana didapati bagi variabel budaya sekolah dengan komitmen guru. Dapatan jelas membuktikan bahawa budaya sekolah mempunyai hubungan secara statistik dengan komitmen guru dalam kalangan guru sekolah rendah di pedalaman atas Sabah. Hal ini bermakna semakin tinggi tahap budaya sekolah akan menyebabkan tahap komitmen guru meningkat.

Dapatan kajian ini adalah sealiran dengan dapatan Rahayu (2012), Manetje dan Martins (2009), Lapiņa, Kairiša dan Aramina (2015), Muhammad Suleman, Adeel dan Muhammad Yameen (2010), Karadağ, Baloğlu dan Çakir (2011), Daud (2007), Acar (2012) dan Raman, Ying dan Khalid (2015). Kesemua dapatan kajian mereka mendapati terdapat hubungan positif yang signifikan budaya organisasi dengan komitmen organisasi. Dapatan kajian mereka menunjukkan tahap budaya organisasi yang tinggi meningkatkan tahap komitmen organisasi. 
Kajian ini mencadangkan sekolah mengamalkan suatu bentuk tingkah laku, kepercayaan, perkongsian nilai yang mana dianggap bersesuaian dalam kehidupan seharian di sekolah kerana budaya sekolah boleh dijadikan jaminan untuk guru kekal bertugas di sekolah. Budaya sokongan daripada pihak pentadbir adalah perlu untuk memastikan guru sentiasa bersemangat dalam melakukan tugasan seharian di sekolah.

Guru besar merupakan pengurus di sekolah rendah dan bertanggungjawab terhadap semua guru dalam sekolah. Menurut Harrison dan Stokes (1993) budaya kuasa bermaksud seorang ahli yang mengurus organisasi dan bertanggungjawab kepada semua ahli dalam organisasi. Di sekolah budaya peranan merupakan peraturan, polisi, prosedur dan deskripsi tugas yang menjadi panduan kepada ahli dan organisasi. Budaya pencapaian merujuk kepada guru yang mempunyai visi dan tujuan yang sama dengan visi dan tujuan sekolah. Manakala budaya menyokong merupakan karakteristik utama dalam perkongsian kepercayaan antara guru- guru dengan sekolah.

Guru yang memiliki tahap komitmen yang tinggi mempunyai matlamat diri yang sama dengan matlamat sekolah. Oleh itu mereka sentiasa berusaha memastikan tugasan dilaksanakan dengan cekap tanpa banyak alasan. Tahap komitmen guru yang tinggi dalam kalangan guru secara tidak langsung akan mengurangkan isu kehadiran lewat, tidak hadir bertugas dan bersara awal dalam kalangan guru. Selain itu, komitmen guru juga akan dapat menjadikan mereka sentiasa peka dengan perubahan khususnya bagi mendepani cabaran pendidikan alaf ke-21 (Jaggil \& Muhamad Suhaimi, 2018).

Sekolah perlu mengamalkan budaya sekolah yang tinggi. Pengamalan budaya sekolah yang tinggi akan mewujudkan suasana kerja yang selesa dan menyebabkan warga sekolah bekerja dengan gembira dan tidak terancam. Budaya sekolah menyediakan panduan dalam menyelesaikan sesuatu tugas dan jalan penyelesaian terhadap permasalahan yang timbul. Justeru kewujudan tahap budaya sekolah yang tinggi akan meningkatkan tahap komitmen guru di sekolah.

Berpandukan penemuan dalam kajian ini, beberapa cadangan lanjutan diutarakan. Dicadangkan, kajian pada masa akan datang di masukkan variabel pengantara untuk melihat hubungan variabel tidak bersandar dan variabel bersandar. Contohnya variabel lokus kawalan dalaman dijadikan pengantara pengaruh budaya sekolah terhadap komitmen guru di sekolah.

\section{Kesimpulan}

Komitmen guru yang tinggi akan menjurus kepada pencapaian cemerlang murid yang akan meningkatkan prestasi sekolah dalam mencapai misi KPM iaitu membangunkan potensi individu melalui pendidikan berkualiti dan visi KPM iaitu sekolah unggul penjana generasi terbilang. Justeru komitmen guru wajar diberi perhatian khususnya pentadbir di sekolah agar matlamat KPM untuk melahirkan insan yang mampu bersaing di peringkat global dapat direalisasikan.

\section{Rujukan}

Acar, A. Z. (2012). Organizational Culture, Leadership Styles and Organizational Commitment in Turkish Logistics Industry. Procedia - Social and Behavioral Sciences. 58, 217-226.

Ambotang, A. S., \& Bayong, N. (2018). The Relationship Between The Burden of Duties and Stress Towards Teacher's Commitment at The Primary School (11-21). Jurnal Pendidikan Bitara UPSI, 11(1), 11-21.

Allen, N.J. and Meyer, J.P. (1990). The Measurement and Antecedents of Affective Continuance and Normative Commitment to the Organization, Journal of Occupational Psychology. 63, 1-18.

Baharom Mohamad. (2012). Pengurusan dan Pentadbiran Pendidikan (Edisi Terhad). Sekolah Pendidikan dan Pembangunan Sosial, Universiti Malaysia Sabah. Sabah.

Becker, H. S. 1960. Notes on the Concept of Commitment. American Journal of Sociology, 66(1), 3240. 
Cheasakul, U., \& Varma, P. (2016). The Influence of Passion and Empowerment on Organizational Citizenship Behavior of Teachers Mediated by Organizational Commitment. Contaduría y Administración, 61(3), 422-440.

Chua, Y.P. (2009). Statistik Penyelidikan Lanjutan Ujian Regresi, Analisis Faktor dan Ujian SEM. Malaysia: McGraw-Hill (Malaysia) Sdn. Bhd.

Cohen, L., Manion, L., \& Morrison, K. (2007). Research Methods in Education. 6th ${ }^{\text {ed }}$. New York: Routledge.

Daud, Y. (2007). Budaya sekolah rendah: Hubungannya dengan kepemimpinan, komitmen organisasi dan pencapaian akademik. Unpublished doctoral dissertation, Universiti Sains Malaysia, Penang.

Erdogan, E., \& Cavli, E. (2019). Investigation of Organizational Commitment Levels of Physical Education and Classroom Teachers. Universal Journal of Educational Research, 7(1), 259-265.

Enginyurt, O., Cankaya, S., Aksay, K., Tunc, T., Koc, B., Bas, O., \& Ozer, E. (2016). Relationship Between Organisational Commitment and Burnout Syndrome: a Canonical Correlation Approach. Australian Health Review, 40(2), 181-187.

Fraenkel, J. R., \& Wallen, N. E. (1996). How To Design and Evaluate Research in Education. $6^{\text {th }}$ ed. New York. McGraw-Hill.

Ghazali Darusalam \& Sufean Hussin. (2016). Metodologi Penyelidikan Dalam Pendidikan: Amalan dan Analisis Kajian. Kuala Lumpur, Malaysia: Penerbit Universiti Malaya.

Hair, J. F., Black, W. C., Babin, B. J., Anderson, R.E., \& Tatham, R. L. (1998). Multivariate Data Analysis, 5(3), 207-219. Upper Saddle River, NJ: Prentice Hall.

Hayden, S.S. (2011). Teacher Motivation and Student Achievement in Middle School Students. Tesis Doktor Pendidikan. Walden University, America.

Hanaysha, J. (2016). Examining the Effects of Employee Empowerment, Teamwork, and Employee Training on Organizational Commitment. Procedia-Social and Behavioral Sciences, 229, 298306.

Harrison, R. \& Stokes, H. (1993). Diagnosing Organizational Culture: Trainer's Manual. Amsterdam: Pfeiffer and Company.

Helvaci, M. A., \& Kiliçoglu, A. (2018). The Relationship Between the Organizational Change Cynicism and Organizational Commitment of Teachers. Journal of Education and Training Studies, 6(n11a), 105-110.

İpek, C. (1999). Organizational Culture and Teacher-Student Relationship in Public High Schools and Private High Schools. Journal of Educational Management in Theory and Practice, 5 (3), 411 442.

Iskandar, I., Majzub, R. M., \& Mahmud, Z. (2009). Kecerdasan Emosi dan Komitmen Pekerjaan dalam Kalangan Pensyarah Universiti di Indonesia (Emotional Quotient and Work Commitment Among Lecturers at An Indonesian University). Jurnal Pendidikan Malaysia| Malaysian Journal of Education, 34(1), 173-186.

Jaggil Apak \& Muhamad Suhaimi Taat. (2018). The Influence Of Teachers' Readiness Towards 21 stCentury Classrom Management. Malaysian Journal of Social Sciences and Humanities (MJSSH), 3(4), 6-22.

Jamal@ Nordin Yunus. (2009). Hubungan Antara Kepimpinan Transformasi dan Budaya Organisasi dengan Organisasi Pembelajaran di Sekolah Harapan Negara Kategori Sekolah Kebangsaan dan Sekolah Jenis Kebangsaan Luar Bandar. Tesis Doktor Falsafah. Universiti Utara Malaysia

Karadağ, E., Baloğlu, N., \& Çakir, A. (2011). A Path Analysis Study of School Culture and Teachers' Organisational Commitment. Policy Futures in Education, 9(5), 573-584.

Karim, F., \& Rehman, O. (2012). Impact of Job Satisfaction, Perceived Organizational Justice and Employee Empowerment on Organizational Commitment in Semi-Government Organizations of Pakistan. Journal of Business Studies Quarterly, 3(4), 92.

Krejcie, R. V., \& Morgan, D. W. (1970). Determining Sample Size for Research Activities. Educational and Psychological Measurement, 30(3), 607-610.

Lapiņa, I., Kairiša, I., \& Aramina, D. (2015). Role of Organizational Culture in the Quality Management of University. Procedia-Social and Behavioral Sciences, 213, 770-774.

Lay, Y. F., Khoo, C. H., \& Ley, C. M. (2016). Pengenalan Kepada Analisis Data Dengan IBM SPSS STATISTICS 19 Dalam Penyelidikan Sains Sosial. Kota Kinabalu: Penerbit Universiti Malaysia Sabah. 
Manetje, O., \& Martins, N. (2009). The Relationship Between Organisational Culture and Organisational Commitment. Southern African Business Review, 13(1), 87-111.

Mauno, S., Kinnunen, U., \& Feldt, T. (2012). Work-Family Culture and Job Satisfaction: Does Gender and Parenting Status Alter the Relationship? Community, Work and Family. 15)1): 101-129.

Messner, W. (2017). The Role of Gender in Building Organisational Commitment in India's Services Sourcing Industry. IIMB Management Review, 29(3), 188-202.

Meyer, J. P., \& Allen, N. J. (1991). A Three-Component Conceptualization of Organizational Commitment. Human Resource Management Review, 1(1), 61-89.

Meyer, J. P., \& Allen, N. J. (1997). Commitment in the Workplace: Theory, Research, and Application. Sage.

Meyer, J. P., \& Allen, N.J. (2004). TCM Employee Commitment Survey Academic Users Guide 2004. London, Ontario, Canada: The University of Western Ontario, Department of Psychology.

Mohd. Majid Konting. (2000). Kaedah Penyelidikan Pendidikan. Kuala Lumpur: Dewan Bahasa dan Pustaka.

Mohamad, R., Kasim, A. L., Zakaria, S., \& Nasir, F. M. (2017). Komitmen Guru dan Kepuasan Kerja Guru di Sekolah Menengah Harian Berprestasi Tinggi dan Berprestasi Rendah di Daerah Kota Bharu, Kelantan. Proceedings of the ICECRS,1(1).

Mowday, R. T., Steers, R. M., \& Porter, L. W. (1979). The Measurement of Organizational Commitment. Journal of Vocational Behavior, 14(2), 224-247.

Muhamad Suhaimi Taat \& Gladys De Rozario. (2014). The Influence Of Academic Attitude And SelfEfficacy Towards Students Achievement In Private Higher Learning Institution, Malaysia. International Journal of Arts and Commerce. 1, 41-50.

Muhamad, S.S., Adeel, R. \& Muhamad, Y. (2010). Impact On Organizational Culture on the Employees" Commitment: Relationship Between Levels Of Organizational Culture with Commitment, KASBIT Business Journal. 3(1), 88-95.

Naderi Anari, N. (2012). Teachers: Emotional Intelligence, Job Satisfaction, and Organizational Commitment. Journal of workplace Learning, 24(4), 256-269.

Nordin Abd Razak, Gusti Ngurah Darmawan \& Keeves, J.P. (2010). The Influence Of Culture On Teacher Commitment. Soc. Psychology. 13, 185-205.

Nordin, N. (2012). Assessing Emotional Intelligence, Leadership Behaviour and Organizational Commitment in a Higher Learning Institution. Procedia-Social and Behavioral Sciences, 56, 643651.

Nurharani Selamat and Norshidah Nordin. (2012). A Study On Teacher's Commitment and Emotional Intelligence In The District Of Klang. Proceedings of the 2nd. International Conference on Arts, Social Sciences \& Technology Penang, Malaysia, 3rd. - 5th.March 2012. Universiti Teknologi MARA, Malaysia.

O'Reilly, C. A., \& Chatman, J. (1986). Organizational Commitment and Psychological Attachment: The Effects of Compliance, Identification, and Internalization on Prosocial Behavior. Journal of Applied Psychology, 71(3), 492-499.

Pallant, J. (2013). SPSS Survival Manual: A Step by Step Guide to Data Analysis Using IBM SPSS $\left(5^{\text {th }}\right.$ e.) England: Mc Graw-Hill.

Palta, A. (2019). Examination of Teachers' Perceptions about Servant Leadership and Organizational Commitment. International Education Studies, 12(4), 36-41.

Paul. M.E. (2012). Organizational Culture and Employee's Job Satisfaction as Mitigated By Gender, Level of Education, and Longevity in a Bureaucratic Oriented Culture. Ph.D Thesis. Capella University.

Rahayu, F. D. (2012). Hubungan Antara Budaya Organisasi dengan Komitmen Organisasi pada Perawat Rumah Sakit Umum Daerah Dr. Syaiful Anwar Malang. Jurnal Psikologi: Jurnal Ilmiah Fakultas Psikologi Universitas Yudharta Pasuruan, 1(2), 61-73.

Raman, A., Ying, L. T., \& Khalid, R. (2015). The Relationsip Between Culture and Organizational Commitment Among Chinese Primary School Teachers. Mediterranean Journal of Social Sciences, 6(2 S5), 93.

Relly Tasap. (2015). Amalan Kepimpinan Servan, Kompetensi Komunikasi, Dimensi Personaliti Guru Besar dan Pengaruh Budaya Organisasi Sekolah Terhadap Motivasi Guru. Tesis Kedoktoran. Fakulti Psikologi dan Pendidikan: Universiti Malaysia Sabah. 
Sabir, M. S., Razzaq, A., \& Yameen, M. (2010). Impact of Organizational Culture on the Employees Commitment: Relationship Between Levels of Organizational Culture with Commitment. KASBIT Business Journal, 3(1), 88-95.

Sarwar, M., \& Ashrafi, G.M. (2014). Students' Commitment, Engagement and Locus of Control As Predictor of Academic Achievement At Higher Education Level. Current Issues in Education, 17(3).

Selden, S.J. (2014). The Relationship Between Perceptions of Organizational Culture And Organizational Commitment Among College And University Counselors And Advisors Who Provide Educational Support To At-Risk Students. Postgraduate Thesis: The Pennsylvania State University, USA.

Shafiq, M., \& Rana, A. R. (2016). Relationship of Emotional Intelligence to Organizational Commitment of College Teachers in Pakistan. Eurasian Journal of Educational Research, 62, 114.

Shagholi, R., Zabihi, M. R., Atefi, M., \& Moayedi, F. (2011). The Consequences of Organizational Commitment in Education. Procedia-Social and Behavioral Sciences, 15, 246-250.

Shapira- Lishchinsky, O. \& Rosenblatt, Z. (2010). Formal Ethical Climate and Voluntary Absence: The Mediation Effect of Organizational Commitment. Journal of Educational Management, 48(2), $164-181$.

Siti Fairuz Hamid, Norshidah Nordin, Afni Anida Adnan dan Norsiah Sirun. (2013). A study on Primary School Teachers' Organizational Commitment and Psychological Empowerment in the District of Klang. Procedia-Social and Behavioral Sciences, 90, 782-787.

Stan, M. M. (2013). Predictors of the Organizational Commitment in the Romanian Academic Environment. Procedia-Social and Behavioral Sciences, 78, 672-676.

Windy Anjilus. (2019). Pengaruh Gaya Kepemimpinan Transformasi, Iklim dan Budaya Sekolah Terhadap Kepuasan Kerja Guru akademik di Sabah. Tesis Doktor Falsafah. Kota Kinabalu, Sabah: Universiti Malaysia Sabah. 